\title{
O conservadorismo patronal da grande imprensa brasileira
}

\author{
Francisco Fonseca \\ Pontifícia Universidade Católica de São Paulo \\ Fundação Getúlio Vargas - SP
}

\begin{abstract}
Resumo
Através da análise da opinião dos editoriais dos quatro principais periódicos diários da grande imprensa, isto é, o Jornal do Brasil, O Globo, a Folha de S. Paulo e O Estado de S. Paulo - aqui considerados "aparelhos privados de hegemonia" -, este artigo procura desvendar os posicionamentos adotados perante a ordem social na Constituinte de 1987/1988, que também contribuem para compreender a reação à Consolidação das Leis do Trabalho. Observa-se, além do mais, as estratégias utilizadas para sua consecução.

Conclui-se que, por mecanismos diversos, a grande imprensa contribuiu decisivamente para a introdução da agenda ideológica neoliberal no país, pois atuou de forma a "divulgar e vulgarizar" as idéias pertinentes a este ideário e de forma militantemente conservadora e patronal.
\end{abstract}

Palavras-chave: Conservadorismo, imprensa, hegemonia, neoliberalismo.

\begin{abstract}
Through opinion analysis of the editorials of the four main daily newspaper, that is, Jornal do Brasil, 0 Globo, Folha de S. Paulo and O Estado de S. Paulo - considered here as "private vehicles of hegemony" - this paper intends to show their positions related to the Constituent's social order of 1987-88th, as long as we consider that it contributes to understand the reaction against the Labour's Laws. We analyse, besides, the strategies used to accomplish them.

We concluded that through several mechanisms the great press has decisively contributed, in a combative way, as for the introduction of the neo-liberal ideas in the country - since it has acted so as to make them known and popular - as for the conservative and patronal ideas.
\end{abstract}

Key words:Conservantism, press, hegemony, neo-liberalism. 


\section{Introdução ${ }^{1}$}

A crescente prevalência da agenda neoliberal que, neste início do século XXI, aprofunda sua oposição aos direitos sociais assegurados historicamente no Brasil pela Consolidação das Leis do Trabalho (CLT) é o que inspira este artigo sobre o posicionamento da grande imprensa brasileira perante dois temas atinentes à "ordem social" elaborados durante o Congresso Constituinte em 1987 e 1988, quais sejam, os direitos sociais e o direito à greve. Esses posicionamentos antecedem o debate contemporâneo acerca do conservadorismo patronal das elites brasileiras, expresso através de um de seus importantes representantes, a grande imprensa ${ }^{2}$. Para além de expressar interesses sociais, os periódicos intermediam relações sociais, notadamente as referidas ao conflito de classe; daí a grande importância de observarmos a posição dos jornais, considerados neste trabalho como aparelhos privados de hegemonia ${ }^{3}$.

Um projeto constitucional explicita uma dada visão de mundo em relação a certos interesses, num contexto em que o embate ideológico torna-se ainda mais ostensivo. O tema "ordem social" implicou enorme controvérsia e a grande imprensa posicionou-se vigorosa e militantemente em relação a ele. Assim, através dos editoriais, que definem, simultaneamente, a linha editorial e ideológica de cada veículo, veremos como a grande imprensa operou nos debates constituintes, sobretudo quando os temas referiam-se aos direitos sociais ${ }^{4}$.

\footnotetext{
${ }^{1}$ Este artigo reflete conclusões de minha tese de doutoramento intitulada Divulgadores e vulgarizadores: a grande imprensa e a constituição da hegemonia ultraliberal no Brasil, defendida no Depto. de História da Universidade de São Paulo em junho de 2001. Esta tese foi viabilizada graças a recursos do Núcleo de Pesquisas e Publicação (NPP) da Fundação Getúlio Vargas de São Paulo.

${ }^{2}$ Considerada aqui pelos jornais Jornal do Brasil (JB), O Globo (OG), a Folha de S. Paulo (FSP), e O Estado de S. Paulo (OESP).

${ }^{3}$ Segundo Gramsci, aparelhos privados de hegemonia são instituições da sociedade civil (distintamente da sociedade política, o Estado, e autônomas em relação a ele) voltadas à sedimentação de um dado consenso, a hegemonia, no sentido de vitória de uma visão de mundo sobre outras, a ser conseguida através da ocupação de espaços ideológicos (GRAMSCI, 2000).

${ }^{4}$ Este artigo não organiza os editoriais citados em estrita ordem cronológica, embora haja um sincronismo entre os mesmos, dado o caráter temático da análise; isto nos permite uma comparação mais sistemática seja (do conteúdo) das posições seja das "estratégias de convencimento" da grande imprensa.
} 


\section{A ordem social na Constituinte: o projeto da grande imprensa}

Um primeiro aspecto importante a ser ressaltado quanto à introdução de novos direitos sociais na Constituição diz respeito ao seu impacto sobre os próprios órgãos de comunicação enquanto empresas. Os interesses representados pelos jornais os opõem a estes novos direitos. O interessante é que se trata, neste caso, de um argumento "particular", critério paradoxal e ironicamente tão criticado pela grande imprensa em relação a seus adversários quanto a temas variados. As teses da futilidade, e sobretudo da ameaça e da perversidade (HIRSCHMAN, 1985) são aqui fartamente utilizadas, demonstrando todo o conservadorismo da grande imprensa, expresso por sua baixa propensão ou mesmo reação à introdução de novos direitos, com vistas à manutenção de seu status quo. Assim, alguns dos direitos sociais propostos, tais como a diminuição da jornada de trabalho, a ampliação da licença-maternidade, a licença-paternidade e o aumento do valor da hora-extra eram tratados como catastróficos à produção. Afirmava-se pois, que desestimulariam o capital de investimento e, em conseqüência, fariam crescer o desemprego. Eram, deste modo, o oposto ao que se desejava. Além do mais, inócuos (estéreis, portanto, fúteis), posto que não seriam respeitados pelo "mundo real" da economia; e ameaçadores aos direitos anteriormente conquistados, caso do mercado formal de trabalho. Como esses argumentos/imagens foram utilizados à exaustão pela grande imprensa no período, apresentamos a seguir uma amostra dos mesmos através de alguns editoriais ${ }^{6}$.

\footnotetext{
${ }^{5}$ As três teses (ou construções retóricas) são assim definidas por HIRSCHMAN (1985):

- Em relação à tese da perversidade: "Não se afirma apenas que um movimento ou política não alcançará sua meta, ou ocasionará custos inesperados ou efeitos colaterais negativos: em vez disso, diz o argumento, a tentativa de empurrar a sociedade em determinada direção fará com que ela, sim, se mova, mas na direção contrária." (p. 18, ênfases do autor).

- Quanto à tese da futilidade, esta estaria fundada no argumento retórico de que "(...) a tentativa de mudança é abortiva, que de um modo ou de outro qualquer suposta mudança é, foi ou será, em grande medida, de fachada, cosmética, e portanto ilusória, pois as estruturas 'profundas' da sociedade permanecerão intactas." (p. 43).

- Por fim, no que tange à tese da ameaça: "(...) assevera que a mudança proposta, ainda que talvez desejável em si, acarreta custos ou conseqüências inaceitáveis de um ou outro tipo." (p. 73). Além do mais, prossegue o autor: "As conquistas e realizações mais antigas, alcançadas a duras penas, não podem ser tomadas como certas, e seriam ameaçadas pela nova reforma." (p. 75, ênfases nossas).

${ }^{6} \mathrm{O}$ papel da imprensa enquanto ator político/ideológico central deve ser observado em diversas esferas. Neste trabalho focamos nossa análise na relação Capital/Trabalho, mas é importante observar como, no que diz respeito por exemplo ao embate ideológico acerca do modelo de desenvolvimento, a imprensa, notadamente a sediada nos países de capitalismo central, posicionou-se em relação a um tema que afeta direta e indiretamente a todos, sobretudo na década de 1990, caso da ascensão do ultraliberalismo. Ao comparar a recepção do keynesianismo e do monetarismo (e da teoria do supply-side) nos Estados Unidos, Wayne Parsons enfatiza sobremaneira o papel da grande imprensa, sobretudo dos jornais financeiros, no que tange ao segundo (o monetarismo), em contraste ao caráter fortemente acadêmico dos adeptos das idéias de Keynes. Portanto, a capacidade espraiadora da grande imprensa articula-se a iniciativas distintas e complementares, como nos casos dos EUA e da Inglaterra, lugares de onde partiram o corpus doutrinário e ideológico de teorias ultraliberais, sobretudo, em termos de teoria econômica, do supply-side. Este papel divulgador e simplificador apontado pelo
} 
Para o JB, haveria uma "obsessão social" por parte dos constituintes: " $A$ proposta de 40 horas é uma daquelas que criam uma espécie de garantia artificial que, na prática, quase ninguém vai respeitar (...)" (JB, 13/07/87, ênfases nossas). Trata-se aqui da tese da futilidade; mas será a tese da perversidade a mais utilizada pela grande imprensa:

"A Constituinte embarcou em um caminho de distribuição de benefícios sociais cujo produto só pode ser um e único: redução da taxa de investimentos, com o conseqüente atraso econômico. (...)" (JB, 28/02/88, ênfases nossas).

A negação dos novos direitos sociais ocorre por meio de uma retórica totalizante, com argumentos que afirmam desde a inadequação de se inserir tais direitos em uma Constituição até seus efeitos deletérios, em franco contraste com o intuito dos constituintes. Estes não estariam se preocupando com o principal, ou seja, a produção da riqueza:

"Por esse rumo, nunca se sai do paternalismo; e o povo continua eternamente dependente. É mais do que tempo de mudar essa mentalidade, que é a própria definição do atraso. (...) O 'social' também está ligado ao desenvolvimento. (..) Mas a visão primária do 'social' não pensa no desenvolvimento - intimamente ligado à livre iniciativa: pensa em criar restrições e ônus para a empresa privada." (JB, 29/02/88, ênfases nossas).

Infere-se, portanto, que a distribuição da renda far-se-ia única e exclusivamente em função do desenvolvimento capitalista, isto é, seria tributária deste, pois dependente dos lucros obtidos pelo Capital. Em termos silogísticos, seria correto inferir-se também o contrário, caso a produção decrescesse. Expressase aqui, claramente, a visão de mundo patronal. Além do mais, o artigo demonstra ainda como a grande imprensa se opõe aos direitos sociais - com vistas à obtenção de uma nova hegemonia, ultraliberal - quando afirma que a "mentalidade atrasada" precisava ser substituída pela visão "moderna" do mundo, que valorizava a "iniciativa privada" pela via do "mercado livre".

autor será fartamente desempenhado pela grande imprensa brasileira em relação a diversos temas, entre os quais o referente à relação Capital/Trabalho (PARSONS, 1990, p.152 e 165). 
Já para o jornal O Globo, que apresenta-se como um vigoroso adepto da "ética do trabalho"7, os direitos sociais estariam:

“(...) na contramão da motivação fundamental e dos interesses do trabalhador; ou a Constituição ideal, na contramão do Brasil real. (...) Sorte pior [dados os efeitos negativos previstos] a experiência faz prever para o aumento (...) da licença remunerada à gestante: a esse aumento corresponderá uma restrição, a restrição do mercado feminino de trabalho. (...) Concessões feitas em total descompasso com os efeitos não prejudicarão apenas os trabalhadores. (...) [mas também a] estabilidade institucional." (OG, 15/10/87, ênfases nossas).

A tese da perversidade é, portanto, igualmente defendida pelo jornal O Globo que, ademais, coloca-se na posição de conhecedor dos interesses dos trabalhadores. Trata-se aqui de uma antiga estratégia da grande imprensa de autonomear-se intérprete da sociedade, inclusive dos trabalhadores, e procurar interferir diretamente no conflito de classes. A imagem catastrófica é reiterada, à luz do que nos ensina Hirschman, constituindo-se num verdadeiro bombardeio retórico. Utilizam-se, para tanto, expedientes ao estilo cassandra, afirmando-se que o futuro certamente seria sombrio caso os novos direitos fossem introduzidos. Para O Globo:

“(...) A produtividade cairá, inevitavelmente. (...) Será lamentável que, por falta de informação e análise aprofundada das questões, venhamos a ter uma Constituição que, na ilusão do avanço, produza o retrocesso no campo das relações de trabalho." (OG, 07/88, ênfases nossas).

Além da perversidade ocasionada pelos direitos sociais, haveria uma inversão do sentido dos direitos ao considerá-los "retrocesso". Em outras palavras, tanto os adeptos da criação de direitos não seriam "progressistas" (consideração expressa em várias circunstâncias), como os direitos em si não seriam um avanço. Trata-se de uma sofisticada estratégia de reformular o próprio vocabulário presente na Constituinte e na sociedade, de tal forma que ideologia (agora ainda mais vigorosamente) seja apenas e tão-somente as propostas dos grupos à "esquerda" e

\footnotetext{
${ }^{7}$ Embora expresse a adesão à ética do trabalho, o Sistema Globo como um todo, historicamente, beneficiou-se da aproximação com o poder, a ponto de obter vantagens em diversos aspectos, tais como financiamentos subsidiados, renegociação favorável de dívidas, dentre inúmeros outros, independentemente, portanto, do mérito e do esforço, que formam os pressupostos da referida ética. Logo, o que o Sistema Globo professa não é necessariamente o que pratica.
} 
dos "populistas" que, por motivos diversos, agiriam em razão das "aparências" e não da "essência" do capitalismo "moderno".

Como se observa, as diferenças de perfis ideológicos e editoriais não impedem a similitude de posicionamentos e projetos dos jornais. Assim, o liberal/conservador OESP, seu similar doutrinário JB, e também o pragmático OG $^{8}$ usarão dos mesmos expedientes. Para O Estado de S. Paulo, por exemplo, "Retrocesso não é avanço". Esse título de um de seus editoriais sintetiza sua histórica visão de mundo, e dever-se-ia indagar sobre o emprego da palavra "avanço":

“(...) Porque se se cuida de reduzir aquela jornada [de trabalho] e premiar indistintamente todos os assalariados com uma estabilidade capaz de atingi-los como autêntico bumerangue, vitimandoos, ocorrerá, sim, autêntico retrocesso; (...) esta (...) palavra (...) [implica] conferir aos que qualifica[m] o demérito de se oporem a tudo o que signifique progresso natural da sociedade. Todos sabem que distribuir a estabilidade com tamanha generosidade nivelaria por baixo bons e maus funcionários (...)

Está claro que nisso existe condenável contra-senso. Quando se pensa em abrir a sociedade para facilitar a ascensão dos melhores e mais capazes, sejam quais forem, venham de onde vierem, procede-se em sentido inverso àquele trilhado (...) A justiça consiste em dar desigualmente aos desiguais - e não, evidentemente, em comprimi-los sob uma forma constrangedora a fim de igualá-los artificial e imerecidamente. (...) [Tal conjunto de direitos] acarretaria pernicioso desestímulo aos melhores." (OESP, 18/06/87, ênfases do jornal, grifos nossos)

\footnotetext{
${ }^{8}$ Caracterizamos, neste trabalho, os jornais do seguinte modo: o JB e OESP afirmam filiar-se a uma tradição doutrinária liberal, em termos políticos e econômicos. Embora aceitemos esta definição, observamos não apenas uma contradição estrutural em relação à aceitação do jogo de interesses, sobretudo dos trabalhadores, conforme ilustram as primeiras passagens que analisamos, como entendemos ser o JB um periódico "pouco conseqüente" em suas posições liberais e OESP um periódico "positivista". Em relação ao OG e à $F S P$, os consideramos "pragmáticos", isto é, desprovidos de uma doutrina a qual se filiem. OG, além do mais, tem como marca o "governismo", isto é, a aproximação umbilical aos governos, e a FSP caracteriza-se por ser, em termos ideológicos ou doutrinários, "volátil" (FONSECA, 2001).
} 
Ora, a introdução de direitos, paralelamente à tese da perversidade (expressa na imagem do bumerangue) e à tese da ameaça (através da imagem do retrocesso), conspurcaria alguns dos valores essenciais da sociedade capitalista, vinculados fundamentalmente ao mérito. O mote "os melhores e mais capazes" sintetiza esta visão tradicional e hierárquica, mais próxima de um "darwinismo social"9, que pretende essencialmente estimular a competição entre a força de trabalho. $O$ caráter conservador desta proposição - defendida há muito por OESP e compartilhada pelos outros jornais com a relativa exceção da FSP - reforça a dominação sobre o Trabalho ao incutir-Ihe valores vinculados à ascensão social, meritocrática portanto. A defesa dos interesses vinculados ao Capital é notória, pois, além de implicar adestramento da força de trabalho ${ }^{10}$, objetiva principalmente impingir a imagem de que basta ao trabalhador esforçar-se para melhorar de vida, versão nacional do "self made man" norte-americano. Embora o conservadorismo de OESP, enquanto visão de mundo, esteja, de certa forma, na "vanguarda" de seus pares, as diferenças entre os jornais, quaisquer que sejam, obnubilam-se quando as questões em jogo referem-se seja aos interesses que os periódicos representam, seja, principalmente, à representação do Capital Global, seja ainda à reprodução do sistema capitalista pela qual se empenham ${ }^{11}$. OESP reforçará o recurso à tese da perversidade ao afirmar que:

“(...) as novas disposições constitucionais irão chocar-se com seus interesses [dos operários]. (...) as medidas 'sociais' aprovadas (...) surtirão efeito bastante maléfico, pernicioso, antes de tudo, para a classe operária. (...) as medidas adotadas não concorrerão para aumentar a produtividade (...) mas para incrementar a automação. (...) o populismo é enganador..." (OESP, 01/03/88, ênfases nossas).

O "argumento" oscila entre a tese da perversidade e a "falsa" consciência da esquerda/populista. Tais justificações do jornal representam variantes de uma mesma raiz: a preservação do status quo no que diz respeito à relação Capital/Trabalho.

\footnotetext{
${ }^{9}$ Nesse sentido, a posição conservadora de OESP vai ao encontro da ideologia ultraliberal, pois esta representa uma "releitura" do liberalismo clássico, na medida em que: "(...) reproduz um conjunto heterogêneo de conceitos e argumentos, 'reinventando' o liberalismo mas introduzindo formulações e propostas muito mais próximas do conservadorismo político e de uma sorte de darwinismo social distante pelo menos das vertentes liberais do século XX." (DRAIBE, 1993, p.86).

${ }^{10}$ Para uma análise histórica do adestramento da força de trabalho, ver BRAVERMAN (1981).

${ }^{11}$ Entende-se por Capital Global a defesa da reprodução do capital em si, independentemente de sua origem ou setor. As classes, contudo, relacionam-se com o Estado de maneira complexa. Por mais que a ideologia ultraliberal pregue a minimização do Estado, é papel do Estado capitalista promover a reprodução da sociedade capitalista através da existência de classes sociais (OFFE, 1984).
} 
Mesmo a FSP que, dentre todos os jornais, manteve uma alegada preocupação com os interesses dos trabalhadores - pois seu mote "Menos Governo, Menos Miséria", esgrimido pouco antes das eleições de 1989, enfatizava a necessidade de o Estado priorizar as áreas sociais ao retirar-se das atividades produtivas $^{12}$-, aderirá a esta cantilena, embora talvez com menor vigor. Segundo o jornal:

“Propostas como a remuneração adicional (...) para o trabalhador em férias, o aviso prévio proporcional ao tempo de serviço e o limite de seis horas para a jornada em turnos ininterruptos, que as lideranças empresariais condenam, inscrevem-se no vasto conjunto de direitos sociais aprovados (...) sem nenhuma consideração mais séria sobre os custos que acarretam. (...) [Representam:] novos custos para o conjunto da população (...) [que] nada mais serão do que o preço que a sociedade terá de pagar pela demagogia de seus representantes." (FSP, 08/07/98, ênfases nossas).

Reitere-se que, mesmo tendo mantido um discurso "social" paralelamente à agenda liberal referente às "reformas do Estado orientadas para o mercado", a FSP também segue a estratégia de seus pares tanto ao utilizar a tese da perversidade como por considerar "demagogia" e "populismo" a adoção de novos direitos sociais quando afirma que seus propositores não se preocupariam com as conseqüências (negativas) da sua introdução. Porém, mais relevante ainda, é o fato de a grande imprensa como um todo, que criticara o Capital nacional por causa de sua baixa responsabilidade e ausência de visão de longo prazo quando da aplicação dos Planos de Estabilização (sobretudo o Plano Collor), adotar novamente posições confluentes às do Capital nacional, como o demonstra a passagem acima. Em outras palavras, além de atuar em uníssono, a grande imprensa enquanto "partido do Capital"13 e "aparelho privado de hegemonia" se "reconcilia", em determinadas

\footnotetext{
${ }^{12}$ A série de reportagens especiais diárias denominadas "Menos Governo, Menos Miséria" procurou vincular ostensivamente a existência de graves desigualdades sociais no país - expressas no lema "menos miséria" - às alegadas e supostamente demonstradas mazelas do setor público, identificadas pela expressão "menos governo"; logo, menos miséria significaria menos governo. Consequentemente, todos os candidatos identificados com o "aumento" das funções do governo quereriam, mesmo que não soubessem/quisessem, mais miséria. As reportagens, que foram comentadas diariamente pelos editoriais, versaram sobre inúmeros temas, tais como: renúncias fiscais, monopólio estatal do Petróleo, índices sociais, burocracia, educação pública, estrutura tributária, subsídios e patrimonialismo, entre tantos outros. Todos os temas abordados procuraram demonstrar ostensivamente a inépcia governamental quanto à "questão social" em razão do atendimento privilegiado a segmentos, especialmente os burocráticos, corporativos e empresariais. É interessante notar que, quando do início da série, no começo de outubro de 1989, o jornal publicou um editorial na primeira página - com o referido título da série - como forma de demonstrar a gravidade do assunto. Tal estratégia é um artifício poucas vezes utilizado pela FSP, o que, por si só, é um indicativo de sua atuação ideológica.
}

${ }^{13}$ Segundo Gramsci, em determinados momentos históricos, certas instituições atuam em nome das classes sociais, sobretudo das classes dominantes, fazendo o papel de partido político no sentido de conferir 
circunstâncias, com o empresariado. E isto não apenas em razão dela própria ser proprietária do meio de produção jornalístico, mas sobretudo em virtude de que, neste momento, os interesses dos representantes e dos representados combinam. se. Trata-se de um interessante jogo de acomodações e reposicionamentos da grande imprensa em relação a determinados pólos de poder, sobretudo o Capital global que representa, embora, por vezes, de forma complexa e tensa.

\section{0 veto radical às greves ${ }^{14}$}

No que tange ao papel da Constituição sobre o direito à greve, uma vez mais observamos uma incrível similaridade entre os periódicos, conforme as características acima apontadas, ou seja, a perspectiva patronal e a representação do Capital Global. Como se trata da ordem legal, é importante analisarmos qual o projeto acerca de um tema tão crucial em uma sociedade que se requer democrática, tal como afirmam os próprios jornais em foco. Segundo o JB, a "(...) liberdade de greve é um abuso conceitual (...)" (JB, 07/07/88, ênfases do jornal). Pode-se inferir, pois, que tal liberdade deveria ser refreada. $O$ fato dos constituintes terem permitido a paralisação das atividades nos serviços públicos, mesmo resguardadas certas condições ao seu funcionamento, seria considerado um absurdo, conceitual inclusive, posto que denotaria perda de autoridade e mesmo fragilidade por parte do Estado ${ }^{15}$, ameaçando assim direitos adquiridos. A FSP afirmaria o mesmo ao considerar que os constituintes estavam permitindo o "direito irrestrito de greve", inclusive nos serviços essenciais, o que, em verdade, era um exagero:

“(...) Um instrumento legítimo de luta se transforma em chantagem contra toda a população, concentra numa categoria específica de trabalhadores [os funcionários públicos] um poder absoluto sobre o conjunto das atividades produtivas do país, com a chancela (...) [da] constituinte (...) [são] artigos condenáveis (...)" (FSP, 15/07/88, ênfases nossas).

\footnotetext{
organicidade aos seus membros e de dirigir suas ações. Este parece ser, neste momento, o papel dos periódicos aqui analisados (GRAMSCI, 2000).

${ }^{14}$ Sobre os papéis de "vetar" e "apoiar", a mídia como um todo julga-se controladora da sociedade mas rejeita ser controlada (FONSECA, 2001).

${ }^{15}$ Note-se que, mesmo que com uma ênfase um pouco menor por parte da $F S P$, os outros três jornais, dentre os quais $O G$ e OESP com ainda mais vigor, valorizam a autoridade do Estado de forma exponencial, sobretudo o respeito à ordem quando a questão se refere à relação Capital/Trabalho e aos movimentos sociais.
} 
O que a FSP diz ser um direito legítimo - a greve - o será apenas em tese, pois o veto contumaz à mesma será uma marca da grande imprensa como um todo. Ao vincular as greves ao exercício da chantagem por parte dos trabalhadores, o jornal expressa um posicionamento típico ao que está referenciado pela tese da ameaça. Isto implica, em conseqüência, uma crítica às leis, que supostamente facilitariam a paralisação do trabalho.

Mas serão O Estado de S. Paulo e O Globo os mais pronunciados radicais opositores das greves, e da organização do trabalho como um todo, estabelecidas na Constituição. Neste aspecto, evidenciar-se-ão fortemente seus posicionamentos patronais. Os referidos periódicos pareciam demonstrar uma ojeriza particular às greves no setor público, dada a ameaça à autoridade que significariam:

"As greves que irromperam em empresas estatais (...) mostram com clareza o quanto a sociedade é impotente diante dos resultados da intervenção do Estado na economia.

(...) São exércitos de empregados que agem com todas as regalias, direitos e mordomias de funcionários públicos, promovendo greves que se iniciaram com reivindicações salariais e ganham, hoje, aspectos nitidamente políticos e ideológicos, que levam à violência.

(...) Tudo isso mostra a incompetência do Estado empresário que, ao centralizar tudo em suas mãos, mostra fragilidade ao negociar com os trabalhadores que sabem ter um opositor incompetente, politicamente minado e, acima de tudo, contaminado pela praga do empreguismo." (OESP, 19/11/88, ênfases nossas)

A percepção acerca do mundo do trabalho estrutura-se sobre a suspeição intrínseca de que os trabalhadores são revolucionários e têm por trás de si "grupos radicais". Trata-se também de uma construção imagética exagerada, dentre tantas outras produzidas estrategicamente pelo jornal que, dessa forma, intenta impedir toda e qualquer possibilidade das greves ocorrerem, sobretudo a partir do Estado, lugar de onde emana o poder político. Nesse sentido, o poder dos funcionários públicos significa uma ameaça ainda mais deletéria, em razão dos riscos tanto à liberdade do Capital como da sociedade.

OG também expressa sua radicalidade contra à aprovação do direito de greve, que classifica como "A porta da anarquia" (título de um importante editorial). Ademais, o direito de greve, uma vez que torna-se "irrestrito" "(...) para todas as categorias de trabalhadores, em todas as circunstâncias, sob quaisquer pretextos (...) significa a porta aberta à desordem e ao caos. (...) É uma abdicação em favor da anarquia." (OG, 17/08/88, ênfases nossas). 
Cabe ressaltar ainda, retomando, a estratégia de superestimar o poder conferido aos sindicatos ao formular-se a imagem de que estes estão nas mãos de "grupos radicais" desestabilizadores ${ }^{16}$. Além do mais, há a omissão deliberada dos constrangimentos interpostos à decisão dos trabalhadores quando estes declaram uma greve, tais como ameaças de demissão, agudizadas pelo desemprego, e a própria legislação, entre outros aspectos. Com isso, quer-se criar a imagem de que ao híper-poder dos sindicatos corresponderia a pusilanimidade da lei e a fragilidade da sociedade, que estariam ameaçadas pela organização dos trabalhadores. A fronteira entre estratégia retórica e visão de mundo (conservadora, patronal e autoritária) é indecifrável. Por fim, o mesmo OG revela e sintetiza cabalmente o conservadorismo autoritário de toda a grande imprensa com a seguinte afirmação:

“No Capítulo 'Dos Direitos Sociais' existe duplicidade de tendências, ambas suficientemente perigosas e capazes de produzir efeitos desastrosos (...)

(...) A pretexto de garantir emprego, retroagimos ao paternalismo intervencionista (...) [caso da] estabilidade no emprego (...) no Art. 6 (...) bem como o regime de 44 horas [que] são a negação da liberdade de trabalho e a consagração do intervencionismo no mercado de mão-de-obra. Já no Art. 10 (...) dispõe-se o contrário, isto é, a não intervenção do Estado, quando se trata de liberdade de greve. (...)

Tudo é disposto de forma a permitir greves sem restrições (...) Os dirigentes da greve decidem e fixam a seu livre-arbítrio os limites da ação de greve. Temos consagrada a contradição do excesso de intervenção do Estado no Art. 6 e da ausência do poder dos governos, no caso de greve. Vedada pelo projeto só a greve de iniciativa empresarial. Dois pesos e duas medidas." (OG, $11 / 10 / 87$, ênfases nossas).

Sem meias palavras, o jornal propugna o "livre mercado" quanto à força de trabalho e o Estado repressor em relação às greves. Em nome do "bem comum", evidencia-se, na verdade, a defesa dos interesses do Capital, seja pela forma como os direitos dos trabalhadores (em sentido amplo) eram concebidos, seja pela demanda de que também o empresariado pudesse, no limite, paralisar a produção (lockout) - demanda meramente retórica e fictícia, pois os interesses empresariais opõem-se a qualquer paralisação das atividades produtivas. Portanto, OG - na verdade, também os demais periódicos, embora com ênfases distintas - quer antepor limites à organização do trabalho, sendo a greve o alvo mais importante, em

\footnotetext{
${ }^{16}$ A imagem de que pequenos "grupos radicais" invariavelmente comandam e manipulam as greves pretende desqualificar qualquer movimento grevista, de antemão, pois lhe retira a legitimidade. Seja por razões estratégicas seja por constituir-se em visão de mundo do jornal, ou ambas, o fato é que tal posicionamento revela a retórica da ameaça.
} 
contraposição a uma espécie de "laissez faire" no mercado de trabalho, o que explica cabalmente a oposição radical a toda e qualquer greve concreta.

\section{A atuação militante conservadora dos periódicos}

Vejamos, agora, um outro aspecto da atuação da grande imprensa como aparelho privado de hegemonia e como ator político/ideológico na Constituinte, à medida em que procurava claramente orientar, dirigir os constituintes, no sentido de conformar os interesses de um capitalismo liberal e conservador. Estes papéis implicam estratégias diversas, entre as quais opor uma suposta maioria liberal existente seja na sociedade, seja na Constituinte, via "Centrão"17, embora tida como silenciosa e pouco organizada - a uma minoria considerada radical e extremamente organizada, a minoria de esquerda. Esta, contudo, teria hegemonia na Constituinte, sobretudo na Comissão de Sistematização, sendo suas ações deletérias à sociedade brasileira.

Embora jamais tivesse mostrado qualquer dado que mensurasse esta relação entre maioria e minoria, a grande imprensa como um todo - mesmo havendo uma menor incidência no caso da FSP - formulou esta imagem com o objetivo tanto de concitar os parlamentares liberais e conservadores (e suas respectivas bases de representação) como o de formar a opinião de seus leitores. Podemos sintetizar esta dicotomia da seguinte forma:

“(...) A maioria quer uma sociedade aberta, com liberdade de criar e produzir, com menor regulamentação estatal. A maioria não tem medo de manter e cultivar o relacionamento internacional (...) a maioria quer um sindicalismo livre, sem paternalismo restritivo do mercado de trabalho e sem a anarquia do grevismo." (OG, 14/08/87, ênfases nossas).

Como se observa, o jornal sabe tanto o que a "maioria" deseja como o que ela rejeita. A alegada confluência entre os dois movimentos por parte da grande imprensa - pois a generalização é perfeitamente observável - com esta suposta "maioria" nada mais era do que um recurso retórico/ideológico. Esta auto-requerida onisciência e o descompromisso quanto à demonstração de dados que comprovassem tal dicotomia demonstravam que a contenda político-ideológica superava a preocupação com qualquer mensuração, pois o que importava era a obtenção da hegemonia (ultraliberal), ameaçada fortemente com as cláusulas

\footnotetext{
${ }^{17}$ O "Centrão" foi assim denominado por aglutinar forças muito distintas que se intitulavam de "centro", mas, em verdade, representava um centro bem expandido, sobretudo à direita.
} 
sociais aprovadas. Afinal, o Brasil era: “(...) Uma nação de pensamento centrista e conservador (...)" (JB, 03/04/87) e este viés teria sido, portanto, desrespeitado pela esquerda, sobretudo o PMDB, que nomeara "esquerdistas" para as principais comissões temáticas encarregadas de comandar o processo constituinte. Mais ainda:

"Entre as duas formas em que se explicita a representação do PMDB (esquerda e moderada), disfarça-se a grande maioria que (...) é também a expressão da grande maioria dos brasileiros. É aí que se encontra o centro de gravidade política brasileira, a grande classe média. A representação política de centro (...) sente-se incomodamente sem condições de externar suas convicções (...) [devido ao] patrulhamento ideológico [da esquerda]" (JB, 05/02/87, ênfases nossas).

Este editorial fecha o círculo, pois a "maioria" é então a classe média, setor também fortemente representado pela grande imprensa. É claro que a maior parte desta classe, embora proletarizada, sobretudo desde 1964, possui valores mais próximos às classes dominantes e por ser leitora de jornais torna-se, portanto, alvo da grande imprensa.

Por outro lado, o fato dos constituintes à esquerda, e ligados a causas populares e nacionais, terem conseguido vitórias importantes para seus pontos de vista fez com que a grande imprensa reagisse de dois modos concomitantes: procurando desqualificar as idéias, interesses e mesmo as pessoas componentes destes agrupamentos, e concitando os "liberais" - eufemismo para toda a sorte de interesses patronais e conservadores - a agirem e a organizarem-se com vistas a derrotar os adversários ${ }^{18}$. Não raro os empresários, nacionais e estrangeiros, e o próprio governo federal foram chamados ao combate, isto é, deveriam exercer todo o seu poder de influência (em sentido amplo) com vistas a barrar a "esquerdização" do país, o que significava, portanto, uma clara e aberta contenda. Tal clareza e ostensividade foram freqüentes e os editoriais são uma síntese desta verdadeira disputa ideológica. A própria linguagem assumia este caráter belicoso, mesmo no que respeitava ao chamamento dos aliados. Segundo o JB:

“(...) Ou o pensamento da empresa privada e das tendências políticas liberais se articulam para produzir um modelo melhor que o modelo autárquico, ou estaremos abrindo o caminho para o fogo que os sopradores das brasas isolacionistas querem acender." (JB, 08/06/87).

\footnotetext{
${ }^{18}$ A beligerância retórica da grande imprensa quanto à organização do Trabalho faz com que a fronteira entre o jogo democrático e o tratamento dado aos adversários torne-se pouco distinguível.
} 
Embora esteja se referindo às restrições ao Capital estrangeiro, este chamamento é extensível a todos os temas-chave identificados pelo jornal. Indiretamente remete-se aqui à tese da ameaça, agora relacionada ao âmbito econômico. A articulação entre Capital e liberalismo é reveladora, mesmo que na grande maioria das vezes o liberalismo esteja genericamente associado à "maioria". O "Centrão", que, na verdade, fora requerido pela grande imprensa, quando surge é saudado como um verdadeiro acontecimento histórico, pois selaria o encontro do "Brasil real" com sua representação. Contudo, toda vez que este agrupamento votou teses próximas aos nacionalistas, por razões diversas, sobretudo corporativas, fora também criticado pelos jornais, que, desta forma, chamavam-Ihe a atenção, procurando com isso "corrigir seus erros", isto é, dirigi-lo. A FSP, mesmo que por vezes tenha criticado o caráter conservador do "Centrão", o apoiou em razão da discussão ideológica maior com a esquerda. Além disso, acreditava que boa parte das medidas aprovada por influência da esquerda, entre as quais as restrições ao capital estrangeiro, seria nociva ao país:

"A defesa de um desenvolvimento equilibrado se deturpa (...) o ímpeto nacionalista se distorce numa defesa da estagnação. São estes os riscos que (...) apresentam-se com especial nitidez. Resta saber se o Congresso constituinte saberá afastá-los, num clima de consenso e ampla sustentação da opinião pública, ou se a opção pela xenofobia e pelo atraso estará (...) consagrada no novo texto constitucional." (FSP, 24/04/88, ênfases nossas) $)^{19}$.

Portanto, a mesma dicotomia aparecia na auto-requerida "moderna" FSP20. A própria idéia de que o "consenso" deveria ser alcançado a partir de sua estruturação na "opinião pública" 21 implicava um círculo vicioso, pois tanto o "consenso" era sinônimo de hegemonia como a opinião "pública" era, em verdade, privada, ou seja, referente a seus formadores, os aparelhos privados de hegemonia.

\footnotetext{
${ }^{19}$ Ao falar de "riscos" o jornal estava professando, em verdade, mesmo que indiretamente, a tese da ameaça.

${ }^{20} \mathrm{O}$ termo "modernidade" foi utilizado largamente pela grande imprensa como um todo, e em particular pela $F S P$ como forma de produzir uma dicotomia com o "atraso", entendido como a intervenção do Estado e a igualdade socialmente induzida.

${ }^{21}$ A expressão opinião pública é invocada pelos jornais, em inúmeras situações, simplesmente para identificar sua própria opinião, que, embora privada, pretende passar-se por "pública". Além do mais, segundo Pierre Laborie, deve-se repelir o uso indiscriminado (e popularizado) desta expressão, na medida em que representa uma verdadeira "armadilha". "Opinião pública" implica movimento, dinamismo, transformação, e não cristalização de uma dada opinião. Em razão das influências dos grupos que formam a opinião "dominante", o seu caráter "público" quer dizer, em verdade, expressão desta dominância, e não discussão descompromissada de temas com vistas a extrair a "melhor posição"(LABORIE, 1991).
} 
Esta equação, embora particularmente cara à $F S P$, era válida para todos os periódicos.

Mas a linguagem beligerante encontrava em OG e em OESP seus representantes máximos. Observemos como as concitações são peremptórias, o que indica o papel político-ideológico dos jornais: no caso de OG, seu governismo inveterado imiscuía-se à defesa do caráter patronal/conservador que requeria para a Constituição, pois tanto o apoio ao presidencialismo como ao mandato de Sarney (tal como este o pretendia, isto é, 5 anos) foram militantemente pressionados pelas Organizações Globo. Quando da redução do mandato para 4 anos, apenas posteriormente mudada, $O G$ assim se posicionou: "Vamos ao plenário; se necessário contra um golpe de Estado, vamos às urnas." (OG, 17/11/87, ênfases nossas). Ir às urnas seria extinguir a Constituinte e buscar uma (supostamente ausente) legitimação popular dos constituintes via eleições. Para além do casuísmo da proposta e do governismo histórico do jornal, importa-nos observar sua participação política, expressa na afirmação através da primeira pessoa do plural, o que, aliás, Ihe é comum em determinadas circunstâncias. Quanto aos temas cruciais das ordens econômica e social, pôde-se observar o mesmo tom. Por exemplo, quando o "Centrão" estruturou-se, com a divisão do PMDB, e conseguiu algumas vitórias importantes, OG o concitou a uma vitória total sobre a esquerda/nacionalistas ao afirmar que:

"Não cabe aos moderados colocarem panos quentes, contemporizando em questões da gravidade (...) [como a] concessão de estabilidade no emprego após três meses (...) A divisão [do PMDB] já existe (...) Só resta consagrá-la. (...) Que os moderados do PMDB assumam a divisão para o restabelecimento da Aliança Democrática (...)" (OG, 07/07/87).

Como se observa, o jornal pressiona, veta, orienta, dirige. Numa palavra, procurava organizar interesses, funcionando como uma espécie de intelectual coletivo do establishment. Sobretudo nos momentos de derrota, mesmo que parcial, assim como nas circunstâncias em que a base governista se dispersou (por motivos diversos), a linguagem e o clima tornavam-se mais exuberantes e candentes, pois:

"Não há outro caminho senão o de todos nos unirmos pondo acima de superadas divergências ideológicas ou de futuras disputas eleitorais os supremos objetivos da Nação." (OG, 05/05/88, ênfases nossas). 
A clareza meridiana desta passagem sintetiza o papel da grande imprensa. Este editorial não apenas fora publicado em primeira página como ocupou largamente a sua parte superior (a área mais nobre e visível do periódico), além de ter sido assinado pelo próprio Roberto Marinho e intitulado justamente "Os supremos objetivos da Nação", sinônimo dos interesses defendidos pelos periódicos. Trata-se da velha estratégia de universalização dos interesses particulares, perfeitamente possível nas entidades unilaterais como a grande imprensa. Para além deste aspecto, percebe-se também claramente como OG chama a atenção dos aliados, cobrando-Ihes unidade.

Ora, se este expediente foi utilizado por periódicos pragmáticos, o que dizer então do tradicionalista OESP ? Este conclamaria os "liberais" à luta com maior incisividade ainda. A cada passo da Constituinte, a grande imprensa foi se posicionando, ora recuando, ora avançando, ora abrindo espaços à negociação. Acompanhar a movimentação dos periódicos nesse momento decisivo da elaboração da nova Constituição encerra muitas lições, dada a importância dos temas a serem votados num espaço de tempo relativamente curto.

Para OESP, portanto,"(...) A hora é de os liberais acordarem - porque depois será tarde." (OESP, 05/02/87). Afinal, houve inúmeras batalhas no Congresso Constituinte: a eleição de membros à Comissão de Sistematização, a modificação do Regimento, as votações nos dois turnos, dentre inúmeras outras. À medida em que os projetos considerados prejudiciais iam sendo aprovados, sobretudo quanto aos direitos sociais, o atônito OESP posicionava-se com vistas a reagrupar as forças aliadas:

"A votação espelha a falta de governo e o caos mental que corroem o Brasil; a incapacidade de os empresários se articularem, de maneira ordenada (...) a indecisão de muitos constituintes, que não sabiam como votar assunto dessa magnitude [os direitos sociais] porque as lideranças empresariais ou políticas não souberam transmitir instruções precisas." (OESP, 11/10/87, ênfases nossas).

De certa forma, este editorial faria uma espécie de mea culpa, pois, aparentemente, a grande imprensa demonstrara inabilidade para dirigir, orientar os parlamentares e os empresários. Para além desse aspecto, era clara a postura de OESP no sentido de cobrar, repreender, instigar, sem jamais "jogar a toalha", pois, tal como em uma luta de boxe, por mais que o lutador esteja perdendo, é papel do treinador orientar-Ihe e dar-lhe estímulo. É isso que sobretudo OESP fez exaustivamente, acompanhado contudo pelos seus pares. Para aquele jornal: 


\begin{abstract}
"(...) os liberais brasileiros têm diante de si ingente tarefa; se não se organizarem para combater o populismo estatizante (...) o Brasil corre o risco de regredir (...)" (OESP, 20/11/87, ênfases nossas).
\end{abstract}

Aqui, a tese da ameaça apresenta-se em toda a sua dimensão, acompanhada pela tese da perversidade, em razão dos efeitos deletérios que os novos direitos trariam à "sociedade brasileira".

\title{
Conclusão
}

Pode-se concluir, através de um editorial de OESP, como a grande imprensa compreende seu próprio movimento homogeneizante. Ao comentar os conflitos entre o empresariado paulista e o Governo Sarney, logo no início do processo constituinte, em que o presidente fizera críticas à grande imprensa nacional, afirmava OESP que:

\section{“(...) O que a imprensa faz é assinalar os erros (e devem ser} muitos e tão evidentes para que se note quase unanimidade na apreciação editorial dos fatos) (...)" (OESP, 21/07/87, ênfases nossas) ${ }^{22}$.

Ora, embora estivesse se reportando a um episódio específico, esta passagem expressa em boa medida a atuação da grande imprensa, que em diversas

\footnotetext{
${ }^{22}$ Como os temas da "liberdade de imprensa" e da introdução de eventuais mecanismos de controle da sociedade sobre os meios de comunicação também estiveram em pauta durante a Constituinte, é interessante observar como foram retratados pelos jornais. Em uma matéria de OESP sobre o posicionamento das associações patronais num encontro específico dos representantes dos meios de comunicação para debater a questão, os presidente da Associação Nacional de Editores de Revistas (Aner), José Antonio do Nascimento Brito (do Grupo Jornal do Brasil), e da Associação Nacional de Jornais (ANJ), Roberto Civita (do Grupo Abril), assim se posicionaram:

[Para o presidente da Aner] “(...) [É] grande engano (...) [os] que pensam que 'os meios de comunicação dirigidos por famílias ou pequenos grupos acionistas produzem jornais antidemocráticos, pois o leitor não é burro e é um erro de qualquer publicação achar que pode enganá-lo por muito tempo.' (...) [Já] "Para o presidente da ANJ, é essencial a defesa da liberdade de iniciativa, privilegiando o talento individual e a economia privada, 'base verdadeira de uma sociedade que ambicione ser politicamente aberta e materialmente rica."' (OESP, 29/04/87, Editorial de Política, seção Constituinte, p.2).

As duas falas expressam, cada qual a seu modo, como a grande imprensa permaneceu requerendo liberdade mas sem qualquer preocupação quanto à responsabilidade pelo seu exercício. Os proprietários dos meios de comunicação pretenderam continuar com a prerrogativa de falar em nome do público e desprovidos de qualquer controle democrático por parte da sociedade, embora fossem órgãos privados.
} 
circunstâncias, sobretudo as que envolveram os interesses do Capital Global, a relação Capital/Trabalho e, a partir das crises dos planos de estabilização da "Nova República", o papel do Estado, posicionou-se em uníssono. OESP apenas corrobora esta conclusão. Uma vez mais as diferenças de perfis editoriais/ideológicos não foram suficientes para que houvesse divergências tanto em relação à forma de atuação como no que tange ao objetivo do projeto político/constitucional ou, numa palavra, no teor da democracia brasileira a vigorar a partir do reordenamento do marco legal, a nova Constituição. Tudo isso apenas confirma o caráter não plural, autoritário e conservador, voltado à vulgarização e à divulgação de idéias da grande imprensa em determinados momentos tidos como críticos. Sua visão de democracia segue historicamente a das elites brasileiras, nas quais a própria imprensa se insere: a democracia autoritária, no sentido de restrita, parcial ${ }^{23}$. Os exemplos analisados neste artigo, sobretudo a relação Capital/Trabalho, são decisivos para esta conclusão, pois demonstram os limites do projeto democrático dos grandes periódicos nacionais.

\footnotetext{
${ }^{23}$ Democracia parcial, restrita ou autoritária tem aqui o sentido conferido por ALMINO (1980), isto é, uma democracia retoricamente universalista, mas efetivamente particularista, pois voltada aos interesses de determinados grupos ou classes.
} 


\section{Bibliografia}

ALMINO, João. Os Democratas Autoritários. São Paulo: Brasiliense, 1980.

BRAVERMAN, Harry. Trabalho e Capital Monopolista: a degradação do trabalho no século XX. Rio de Janeiro: Zahar, 1981.

COCKETT, Richard. Thinking the Unthinkable: Think-Tanks and the Economic CounterRevolution, 1931-1983. London: HarperCollins, 1995.

DAHL, Robert. Polyarchy: Participation and Opposition. New Haven: Yale University, 1972.

DRAIBE, Sônia. As Políticas Sociais e o Neoliberalismo. REVISTA USP: Dossiê Liberalismo/Neoliberalismo, n 17, março/abril/maio, 1993.

DICIONÁRIO HISTÓRICO-BIOGRÁFICO. Centro de Pesquisa e Documentação da FGV/RJ (CPDOC), 2002.

EAGLETON, Terry. Ideology - An Introduction. Oxford, 1991.

FONSECA, Francisco C. Pinto da. 1994. A Imprensa Liberal na Transição Democrática (1984-1987): Projeto Político e Estratégias de Convencimento. Unicamp, Departamento de Ciência Política, Campinas, 1994.

2001. Divulgadores e vulgarizadores: a grande imprensa e a constituição da hegemonia ultraliberal no Brasil. Tese de Doutoramento em História. Departamento de História, USP, São Paulo, 2001.

A democracia virtual: a mídia sem freios e contrapesos. In IANNI, Octavio et al. (org). Desafios da Comunicação. Petrópolis: Vozes, 2001.

GENTILI, Pablo e SADER, Emir (orgs.). Pós-Neoliberalismo - As Políticas Sociais e o Estado Democrático. Rio de Janeiro: Paz e Terra, 1995.

GRAMSCI, Antonio. Cadernos do Cárcere (5 Vols.) Rio de Janeiro: Civilização Brasileira, 2000. HIRSCHMAN, Albert. A Retórica da Intransigência. São Paulo: Cia. das Letras, 1985.

IANNI, Octávio et. al. (orgs.). Desafios da Comunicação. Petrópolis: Vozes, 2001.

LABORIE, Pierre. Histoire politique et histoire des représentations mentales. In PESCHANSKI, Denis et al (orgs.). Histoire Politique et Sciences Sociales. Paris, Editions Complexe. Paris: Editions Complexe, 1991. 
OFFE, C. Problemas Estruturais do Estado Capitalista. Rio de Janeiro: Tempo Brasileiro, 1984.

PARSONS, Wayne. The Power of the Financial Press. New Jersey: Rutgers University Press, 1990. 